\title{
Comment on "Examining Burnout, Depression, and Attitudes Regarding Drug Use Among Lebanese Medical Students During the 4 Years of Medical School"
}

\author{
Marcela Almeida $^{1}$ (D) John Fromson ${ }^{1}$ \\ Received: 6 March 2018 / Accepted: 3 April 2018 / Published online: 10 April 2018 \\ (C) Academic Psychiatry 2018
}

To the Editor:

We read with great interest the article by Talih et al. in a recent issue of the journal [1]. The authors performed a crosssectional study to evaluate the prevalence of burnout, depressive symptoms, anxiety symptoms, and attitudes toward substance use in medical students. They detected high rates of depression, burnout, and suicidal ideation among medical students in the Middle East. The authors should be congratulated for performing a well-designed study in an important topic in graduate medical education and overall physician practice $[2$, 3]. Additionally, the need to identify specific areas for potential interventions to prevent burnout in medical students is an innovative concept that needs to be further explored $[4,5]$.

Although the study by Talih et al. was well designed and well conducted, there are some questions regarding it that need to be clarified in order to determine the validity of the results. First, the analysis of burnout across medical school years would need to be adjusted for confounding factors. This would validate the authors' important findings. Second, the authors reported a $42 \%$ response rate for the survey. The potential for generalization of the results relies on excluding response bias by contrasting the characteristics of nonrespon-

Marcela Almeida

malmeida2@bwh.harvard.edu

1 Brigham and Women's Hospital, Boston, MA, USA dents with respondents of the survey. Lastly, the authors did not present common factors associated with burnout (e.g., working hours and control over personal life), and these factors can significantly change the study results.

We would welcome comments to address these issues as they were not discussed by the authors. This would help to further validate the findings of this important study.

\section{Compliance with Ethical Standards}

Disclosures On behalf of both authors, the corresponding author states that there is no conflict of interest.

\section{References}

1. Talih F, Daher M, Daou D, Ajaltouni J. Examining burnout, depression, and attitudes regarding drug use among Lebanese medical students during the 4 years of medical school. Acad Psychiatry. 2018; https://doi.org/10.1007/s40596-017-0879-x.

2. De Oliveira GS Jr. Biological evidence of the impact of burnout on the health of anesthesiologists. J Clin Anesth. 2017;41:62.

3. Louie AK, Trockel MT, Balon R, Coverdale JH, Beresin EV, Brenner AM, et al. "Physician Wellness" as Published in Academic Psychiatry. Acad Psychiatry. 2017;41:155-8.

4. Vinson AE, Zurakowski D, Randel GI, Schlecht KD. National Survey of US academic anesthesiology chairs on clinician wellness. J Clin Anesth. 2016;34:623-31.

5. Gonzalez LS, Donnelly MJ. A survey of residency program directors in anesthesiology regarding mentorship of residents. J Clin Anesth. 2016;33:254-65. 